\title{
BIBLIOTECA PÚBLICA: DO SÉCULO XIX PARA O XXI
}

\section{LUÍS MILANESI}




\section{RESUMO}

As bibliotecas públicas brasileiras estão entre dois tempos: o seu próprio modelo, que remete ao século XIX, e a necessidade de trazê-las para o século XXI. Enquanto o primeiro tempo deve ser superado, o segundo ainda deverá ser alcançado, como desafio técnico e político-social.Enquanto o primeiro oferece recursos conhecidos e acessíveis, o segundo depende de decisões que ultrapassam o campo técnico. As bases desse esboço ligam-se ao uso da tecnologia para preservar e fortalecervalores da informação pública: democracia, diversidade e informação necessária e de qualidade como base do desenvolvimento material e imaterial da nação.

Palavras-chave: biblioteca pública, informação, democracia.

\section{ABSTRACT}

Brazilian public libraries are poised between two eras: their own model, which dates back to the 19th century, and the need to bring them up to the 21st century. While the first era is likely to be overcome, the latter is yet to be experienced, as it is a social, political and technical challenge. While the first offers accessible and known resources, the latter hinges on decisions which go beyond technical competence. The bases of this plan are linked to the use of technology to preserve and strengthen values of public information: democracy, diversity, and necessary and quality information as a foundation for the material and immaterial development of the country.

Keywords: public library, information, democracy. 


\section{CENA BRASILEIRA}

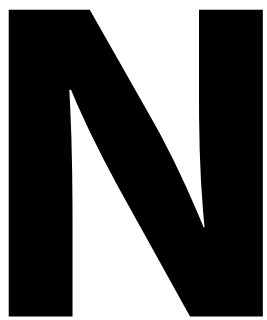

a praça central de uma pequena cidade no interior do Brasil se pode observar, simultaneamente, ações que representam dois tempos históricos: os séculos XIX e XXI. De um lado, a Biblioteca Pública Municipal e, num banco do jardim, um garoto com o seu tablet. Distância física: 15 metros; distância temporal: um século.

A prefeitura local é a responsável pelo acesso livre à Internet e também pela biblioteca. Ela, nos últimos tempos, progressivamente, perdeu seu público e, neste ano de 2013, está quase vazia. A sua conformação e a sua organização espacial situam-se no padrão que pouco mudou desde 1811, quando foi criada em Salvador a primeira biblioteca pública no Brasil. Basicamente o cenário é o mesmo: estantes com livros, mesas e, quase sempre, uma divisória entre os livros e os seus leitores.

A cena descrita é uma síntese metafórica do corte profundo que separa a cultura em dois tempos. O primeiro mostra milhares de anos de registro do pensamento e da sensibilidade humanos em suportes físicos: tabletes de argila, papiro, pergaminho e papel, os quatro materiais que, em alguns formatos, constituíram os acervos - de Nínive à Biblioteca do Congresso em Washington ou à pequena biblioteca pública acima referida.

Nesse longo período um invento, a imprensa móvel de Gutenberg, criou, no século $\mathrm{XV}$, um marco divisório na civilização humana: a imprensa. Ela permitiu o revolucionário barateamento dos livros, que substituíram os códices, caríssimos, pois elaborados um a um, que em bibliotecas podiam permanecer acorrentados. O aumento da produção editorial propiciou a formação e multiplicação das bibliotecas. Elas cresceram em número e proliferaram pelo planeta, tendo o seu epicentro no Velho Mundo. Estavam presentes em instituições de estudos, estabelecimentos religiosos e, posteriormente, nas cidades por iniciativa das administrações locais. A máxima expansão em quantidade e qualidade ocorreu no século XX nos Estados Unidos, onde, num período, prevaleceu a ideia de que "abrir uma biblioteca" seria igual a "fechar uma cadeia".

\section{O CENÁRIO PRÉ-INTERNET}

A velocidade da informação esteve, por séculos, atrelada à velocidade de locomoção
LUÍS MILANESI

é professor titular da Escola de Comunicações e Artes (ECA) da USP e autor de Biblioteca (Ateliê). 
dos seres humanos. Assim, se um estudioso da Idade Média tivesse conhecimento da existência de um manuscrito pelo qual se interessasse, teria de se locomover durante dias para chegar a ele. Com a proliferação das obras impressas e das bibliotecas, tornou-se mais fácil a obtenção do desejado - ainda que fosse necessário saber em qual biblioteca encontrar o texto procurado. A partir do século $\mathrm{XX}$, foram criadas várias estratégias para diminuir o tempo entre a necessidade manifesta de informação e o atendimento. Como o tempo tem um custo, a disseminação de informação tornou-se um fenômeno econômico no qual a relação custo/benefício ocorre pela precisão e velocidade do atendimento.

\section{Acervos precários}

A produção bibliográfica, progressivamente maior, não garantiu a existência de bibliotecas de acesso público com acervos satisfatórios. Nessas bibliotecas, a precariedade do acervo é crônica. O público tem interesse diversificado e não há correspondência entre esse desejo e as obras disponíveis. Quanto maior for a heterogeneidade do público, maior será a dificuldade de formação de acervo. As cidades, mesmo as menores, mostram uma diversidade sociocultural complexa. Nelas habitam classes sociais diferentes, grupos com escolaridade diversa, interesses múltiplos que se multiplicam pelas faixas etárias. A possibilidade que tem uma biblioteca municipal de oferecer acervo que atenda a interesses de adultos e crianças, doutores, alfabetizados e analfabetos, operários, donas de casa, adolescentes e de outras categorias é, estatisticamente, diminuta.

Os dados do IBGE mostram que $73 \%$ dos municípios brasileiros têm até 20 mil habitantes. Portanto, cerca de 4.050 cidades com prefeituras, escolas e delegacias de polícia, têm população urbana inferior a 15 mil habitantes agrupados em segmentos com perfis diferentes. A esse quadro acrescentam-se os recursos mínimos do orçamento municipal para a educação/cultura e se obtém um re- sultado em que a criação e a manutenção de bibliotecas úteis são tarefas inviáveis. Os eventuais leitores espalhados por milhares de municípios brasileiros deverão contentar-se com o que existe na biblioteca municipal e, raramente, encontrar o que procuram.

Os acervos impróprios - aqueles que não se relacionam com o público ao qual se destinam - foram criados em décadas, de forma fortuita, sem previsão, sem planejamento. Como raramente existiram no orçamento dos municípios recursos para compra de livros e política continuada para tal, os impressos foram juntados aleatoriamente, ora provenientes de doações governamentais desnecessárias, ora de faxinas domésticas. As doações estaduais e federais, provavelmente, foram as maiores provedoras de livros. $\mathrm{Na}$ área federal, o precursor foi o Instituto Nacional do Livro, criado em 1937 no Estado Novo. O INL implantou uma prática que foi a síntese da política governamental para as bibliotecas: doação ocasional de livros. Os pacotes com os mesmos livros eram remetidos para bibliotecas diferentes e destinadas a públicos específicos. Nunca houve a preocupação de formar acervos básicos essenciais. O resultado disso foi a formação e a ampliação de acervos de pouco interesse.

Essa precariedade de acervo foi um dos fatores que levaram ao esvaziamento das bibliotecas municipais. Com a adaptação delas, no período pré-Internet, à demanda estudantil e suas pesquisas, $o$ acervo utilizável foi reduzido a poucos livros, quando não a uma enciclopédia. Esse rumo tomado excluiu a ideia do acervo amplo para atender a uma demanda heterogênea. Conformou-se à necessidade visível de atender ao público real: crianças e adolescentes que deveriam, obrigatoriamente, fazer "pesquisa". Ressalta-se que as bibliotecas públicas foram procuradas pelos escolares em face da inexistência de bibliotecas nas escolas. As bibliotecas municipais, portanto, para que fossem reconhecidas como úteis, só deveriam manter o acervo necessário para atender aos escolares. Dessa situação resultou o cenário de muitos 
alunos, crianças e adolescentes: poucos e desatualizados livros e um número mínimo de adultos. Com a Internet disseminou-se a prática de copia-e-cola à guisa de pesquisa, e isso motivou a atual e crescente debandada de escolares das bibliotecas.

\section{A organização local}

Acervos precários e desorganização quase sempre estiveram juntos. As bibliotecas públicas não dispunham e não dispõem de competência profissional para organizá-las. As políticas públicas de cultura, setor onde quase sempre se alojam as bibliotecas, nunca deram prioridade à contratação de recursos humanos próprios à administração de bibliotecas públicas. Além disso, os salários pagos pelas prefeituras são insuficientes para atrair profissionais formados em instituições sediadas em capitais ou cidades de grande porte. Além disso, há escassez de competência profissional especificamente voltada à informação pública. As instituiçõos de ensino superior que formam bibliotecários raramente se direcionam para esse campo - que vai muito além das habilidades técnicas convencionais. Essa falta foi um dos fatores determinantes da precariedade dos serviços oferecidos pelas bibliotecas, inclusive a disponibilidade de acervos apropriados. E não há perspectiva, que não seja em longo prazo, de formar profissionais competentes para substituir o quadro funcional provisório atual. Há, portanto, um entrelaçamento de situações que leva o Brasil a um descompasso com o tempo. O esforço de superação a ser feito exige políticas culturais que transportem as bibliotecas do século XIX para os centros de informação e cultura como uma exigência do século XXI.

Apesar de tentativas já feitas, é difícil estabelecer qual seria o número mínimo de obras para atender a uma população de 10 mil habitantes. Por "número mínimo" entende-se o conjunto de obras que possa cobrir os campos do conhecimento humano com ênfase nas áreas de maior interesse para o Brasil. Essa coleção básica teria o número mínimo de 5 mil títulos que, multiplicado por 5.570 municípios, daria mais de 27 milhões de obras. Se esse número de obras fosse adquirido, resultaria em despesa que jamais seria coberta pelos governos municipais, estaduais e federal. No entanto, todos os municípios brasileiros teriam em suas bibliotecas Dom Casmurro e outras obras essenciais. Como não basta dispor de acervos, mesmo que sejam fundamentais, mas também ter profissionais aptos a torná-los úteis para a população, os gastos públicos iriam muito além da aquisição. $\mathrm{Na}$ perspectiva atual, essa demanda e a exiguidade de recursos estariam muito além das possíveis respostas dos órgãos governamentais.

Além desses números inibidores há outro componente impreciso e complexo: como cada municipalidade desenha a sua política cultural, não há como garantir que ela priorize a biblioteca pública. De um modo geral, os dirigentes municipais têm a expectativa de que o estado ou a União, de preferência ambos, encontrem as soluções para garantir a existência de boas bibliotecas em cada cidade. A maioria vê a biblioteca como um acessório prescindível - e o quadro atual mostra isso - em face de outras demandas muito mais compreensíveis para os prefeitos, vereadores e até mesmo pela população. Essa visão construída numa sociedade com quatrocentos anos sem livros dificilmente será alterada nas próximas gestões municipais. Esperar que em cada cidade brasileira, isoladamente, possa haver um movimento em busca da cultura/informação como alavancas do desenvolvimento leva à crença numa inflexão da trajetória desses quatro séculos. As mudanças poderão vir, mas não mediante o uso das ferramentas tradicionais das bibliotecas. A biblioteca do século XXI pede alternativas.

\section{A ERA DO PAPEL E O INÍCIO DA DIGITALIZAÇÃO}

O crescimento acelerado de publicações foi um dos fatores que impuseram limites às bibliotecas: não era possível manter coleções 
em permanente expansão sem a ocorrência de prejuízos em relação ao acesso. Além disso, poucos centros mundiais poderiam sustentar financeiramente a atualização de suas bibliotecas. Esse impasse forçou a criação de novos caminhos para tornar acessível a informação procurada.

Dos esforços, principalmente do belga Paulo Otlet (1868-1944), surgiu a documentação que, sendo uma evolução da biblioteconomia, mostrou-se como um novo campo. Ainda, em 1966, quando foi criada a Escola de Comunicações Culturais, depois Comunicações e Artes (ECA), a biblioteconomia e a documentação não cabiam num mesmo departamento. Por isso foram criados dois. No ano seguinte, o bom senso reuniu-os num único departamento, o de Biblioteconomia e Documentação, como se fossem dois campos distintos.

Nesse início, a biblioteconomia estava centrada na Classificação Decimal de Dewey (criada em 1876) e no Anglo-American Cataloguing Rules (primeira edição, 1967). A documentação trouxe para a linha de frente a Classificação Decimal Universal, delineada no final do século XIX, e três novos elementos que tornavam as seculares fichas catalográficas obsoletas: o microfilme, a microficha e, logo a seguir, a utilização do computador como ferramenta a serviço da informação científica.

A digitalização como fenômeno tecnológico é da segunda metade do século XX. Rapidamente evoluiu até se tornar equipamento de uso pessoal e doméstico, permitindo converter em arquivos digitais textos, imagens e sons. Essa tecnologia concretizou o que era o objetivo dos pioneiros documentalistas: diminuir grandes acervos de tal modo que o espaço físico deixasse de ser um problema relevante. Assim, bibliotecas gigantescas puderam ser transferidas - de forma organizada para dispositivos facilmente manipuláveis.

O surgimento da digitalização abriu um novo campo e novas perspectivas para a área da informação. A biblioteconomia tradicional ficou circunscrita à organização dos suportes físicos; a documentação criou novas ferramentas para organizar o "caos bibliográfico" e se valeu das microformas para multiplicar acervos em espaços mais reduzidos. A digitalização trouxe a possibilidade da redução física de acervos e o desafio de organizar volumes progressivamente maiores de informação para torná-la utilizável. Neste início do século XXI, a perspectiva é clara: os suportes físicos são superados, sendo já criados no ambiente digital os textos, as imagens e os sons. No âmbito do livro impresso em papel pode ser prognosticada a digitalização de tudo que o homem produziu desde Gutenberg, agora armazenado na "nuvem". Até mesmo para preservar a memória da produção humana, o objeto livro permanecerá como testemunho de um tempo, preservado em espaços com luz, temperatura e umidade controladas. No entanto, para uso, progressivamente os livros deixam de ser objetos físicos e tornam-se digitais, armazenados em computadores. Com isso abrem-se novas possibilidades de acesso e uso. A partir de um determinado momento, os suportes físicos deixarão de existir e a informação, a comunicação e a criatividade humanas se expressarão por meio de recursos digitais.

\section{As bibliotecas na nuvem}

$\mathrm{O}$ "como organizar" exige que se estabeleçam regras, normas. Quanto mais diversificados e numerosos os objetos organizáveis, mais complexas e extensas são as instruções para mantê-los na ordem desejada. Em séculos passados o isolamento entre as raras bibliotecas levou a uma diversidade de normas. Com a proliferação delas e o encurtamento da distância entre uma e outra, a tendência foi a adoção de regras prontas já utilizadas anteriormente. Essa uniformização de regras não só facilitava o trabalho dos bibliotecários como, mais tarde, mostrou-se imprescindível para as atividades em cooperação. Se, em séculos, a organização dos acervos marcou divisões entre países e grupos, cada um considerando as suas regras e práticas as melho- 
res, o mesmo ocorre neste momento inicial de criação de bibliotecas digitais. Tais divisões, muitas vezes em conflitos no cenário de congressos internacionais, caracterizaram-se como barreiras à cooperação entre as partes. Se essas contendas pré-Internet duravam décadas e eram vistas com clareza, na situação presente, na qual o processo produtivo com as ferramentas digitais é muito mais acelerado, a percepção do desenvolvimento de produtos, suas similaridades e conflitos, exige atenção redobrada daqueles que se dedicam ao estudo e à prática com bibliotecas na nuvem.

Nos últimos dez anos, excluindo-se as iniciativas de interesse claramente comercial que atuam dentro das raias próprias da concorrência, ações de universidades e de grandes bibliotecas apresentam e apregoam as qualidades de suas soluções. E, assim, uma série de produtos é apresentada e mostrada como as melhores respostas para garantir ao usuário a busca precisa, rápida e segura. Essa proliferação tende a diminuir, porque falar a mesma língua custa menos. Por isso a tendência é a da uniformização das normas, que conduzirá à desejável associação entre plataformas. O trabalho colaborativo será condição imprescindível para que, na era digital, não se tenha um novo "caos bibliográfico".

O fundamental a ser alcançado é a facilidade de acesso, permitindo a qualquer cidadão encontrar o que deseja com precisão e rapidez.

\section{OS ÓBICES JURÍDICOS}

Quando são citadas as vantagens de acesso a bibliotecas digitais, de imediato, como entrave, é mencionada a Lei 9.610, de 1998, conhecida como a Lei do Direito Autoral. A velocidade das mudanças tecnológicas tem sido maior do que a capacidade dos legisladores em aprovar leis e normas que se aplicam a elas.

O domínio público de uma obra ocorre depois de setenta anos da morte do autor. Esse é um princípio quase universal, significando que a maior parte das obras estará disponível somente depois de um século da publicação. Excluídos os clássicos, que são permanentes, todo o acervo de uma biblioteca pública, fortemente centrada na contemporaneidade, estaria sujeito à referida lei. Portanto, a digitalização de um texto, som ou vídeo durante décadas só poderá ser efetuada com a explícita autorização do detentor dos direitos autorais. Apesar das discussões que isso motiva, não há muito a fazer, pois a lei é clara. No entanto, isso não encerra o assunto e não resolve os problemas. Ao contrário, abre outros.

A digitalização das obras de uma biblioteca de acesso público não tem o objetivo primeiro de preservá-las. E, progressivamente, o acervo digitalizado suplantará em número as obras em papel e outros materiais. Nas bibliotecas tradicionais, o que se busca é a circulação do acervo. O público tanto poderá consultá-lo no local ou fazer empréstimo de obras. Na legislação atual isso não afeta nenhum dispositivo da Lei do Direito Autoral. No entanto, se uma obra contemporânea for digitalizada e ficar à disposição dos leitores, isso poderá significar o acesso universal a ela, afetando um elo da cadeia editorial: a distribuição.

Essa e outras questões surgirão quando da efetiva implantação de uma biblioteca pública digital. A cada nova situação de divergência entre as partes interessadas na cadeia informativa, os especialistas na legislação do direito do autor serão chamados.

É provável que a legislação atual, com as mudanças ocorridas no âmbito da Internet, seja alterada. Todos os esforços serão direcionados para práticas que facilitem o acesso público à informação.

\section{POLÍTICAS DE LEITURA, POLÍTICAS DE INFORMAÇÃO: DIREITO DO CIDADÃO}

Os processos tecnológicos para a criação de uma biblioteca pública digital são conhecidos e aplicáveis e, certamente, são menos custosos que a biblioteca convencional. As 
políticas culturais, no Brasil, na prática nunca deram prioridade às bibliotecas públicas e ao acesso à informação. $\mathrm{O}$ resultado desse descaso de décadas é o atual panorama de bibliotecas vistas como repartições municipais de pouco e decrescente uso. Elas, nominalmente, existem em quase todos os municípios brasileiros. No entanto, a maioria delas não se vincula às atividades culturais e nem mesmo à informação. A tendência é que se extingam sem que haja decisões locais em busca da recriação de seu papel. Um dos motivos disso, talvez o principal, é a transferência da tarefa de pesquisar para os sites de busca. A pergunta é elementar: o que substituirá as bibliotecas de livros e revistas impressos? Se estes podem ser digitalizados e arquivados, permanecendo íntegros nos computadores, a resposta aponta para a nuvem.

Considerando-se apenas o acervo, a alternativa é a criação da biblioteca pública digital de livre e fácil acesso. Inclusive porque a nuvem, sendo mais completa, é menos onerosa.

\section{Criação da biblioteca pública básica}

A primeira pergunta que, inevitavelmente, é feita quando se discute a criação de uma biblioteca/informação pública é relativa ao acervo: o que deve ser digitalizado e organizado na nuvem, prioritariamente? Os critérios para a formação do acervo de uma biblioteca pública municipal, pelo menos teoricamente, são: 1) obras consideradas fundamentais pela importância artística, pelo seu significado histórico, pelo conteúdo informativo; 2) textos que atendam a demandas locais. Como foi visto, a formação de acervos das bibliotecas públicas brasileiras raramente segue esses determinantes, uma vez que elas dependem de doações circunstanciais e eventuais aquisições sem critérios claros. $\mathrm{Na}$ seleção de obras de um acervo digitalizado deverá prevalecer o critério de qualidade determinado por especialistas.

São conhecidas algumas iniciativas visando estabelecer uma lista básica de textos para bibliotecas públicas. A mais destacada foi construída na Colômbia, a Lista Básica de Libros para Bibliotecas Publicas, por iniciativa e responsabilidade da Universidad de Antioquia, com 3.676 obras listadas, inclusive infantojuvenis. Essa e outras listas de obra são úteis não apenas para formar acervos básicos de bibliotecas públicas, mas igualmente para a aferição da qualidade dos acervos já existentes.

A construção dessas listas é tarefa complexa, pois abarca todos os campos do conhecimento e cada obra é escolhida a partir de várias possibilidades. Para a formação do acervo básico brasileiro a ser digitalizado, prioritariamente, deverão ser consultados especialistas. Assim, para temas como, por exemplo, "psicanálise", "economia agrícola", "preservação ambiental", somente especialistas, e sempre mais de um para cada tema, poderão dizer quais são as obras essenciais. A relação de assuntos dada pela Classificação Decimal de Dewey ou pela Classificação Decimal Universal é ampla e, necessariamente, atualizada anualmente. Isso pelo surgimento não só de obras novas sobre assuntos já existentes, mas também de obras sobre novos assuntos. Mesmo aplicando o máximo rigor, essas listas de prioridades, renováveis periodicamente, serão incompletas e falhas. Mesmo assim, imprescindíveis.

Parte substancial da "biblioteca pública digital brasileira" pertencerá ao campo da literatura. De imediato, não será possível integrar no acervo digital todas as obras de todos os autores. O critério deverá ser dos especialistas, que determinarão a ordem de digitalização. Além da escolha das obras, é imprescindível que seja indicada a edição que atenda aos objetivos de um acervo público de uso geral. Assim, entre a primeira edição de Dom Casmurro, de Machado de Assis, que interessa aos especialistas, e uma edição contemporânea, com a ortografia atualizada, a opção deverá ser pela última.

Além das obras mais representativas da história da literatura e do pensamento brasileiros, também serão incluídos os re- 
presentantes da produção de outros países.

As obras contemporâneas constarão da lista básica, e novos títulos serão selecionados anualmente. Por isso, há a necessidade de uma nova tarefa: a curadoria de acervos. Se isso ficava a critério de milhares de selecionadores de obras para as bibliotecas municipais existentes, agora, havendo uma única biblioteca digital, a formação do acervo público ficará a critério de especialistas.

Não se pode determinar qual seria o tamanho de um acervo essencial para o Brasil. Mas pode ser fixado por outros critérios um número para o acervo inicial, entre quatro e cinco mil títulos (entre impressos e audiovisuais), que será ampliado constantemente. Com o desenvolvimento das práticas de cooperação entre bibliotecas digitais, será possível incluir outras bibliotecas digitais. Isso permitirá que o jovem citado no início deste texto tenha acesso, de sua pequena cidade, a quaisquer obras da grande biblioteca universal.

\section{Aquisição de obra digitalizada}

Ao se fazer um paralelo entre a biblioteca de papel, que por vários séculos foi o registro e a fonte do conhecimento humano, e as novas possibilidades tecnológicas, algumas ações deverão ser, mais do que adaptadas, recriadas.

A seleção, mesmo sendo complexa, não difere dos critérios de formação tradicional do acervo. O segundo passo - a aquisição - já conduz a interrogações. Tratando-se de livro impresso, no ato da aquisição que um município faz de Grande Sertão: Veredas, está incluído no pagamento o valor referente aos direitos autorais devido aos herdeiros de João Guimarães Rosa. E o livro pode ser lido na biblioteca ou retirado pelo leitor. A Lei do Direito Autoral exige que se pague uma vez no ato da compra, mas a leitura está liberada para todos os leitores - até o fim físico da obra.

Na biblioteca digital os textos de domínio público serão incorporados e acessados sem nenhum óbice legal. Mas, tratando-se da obra acima referida, como deverá ser o procedimento de acordo com a lei? A digitalização só poderá ser realizada mediante termo formal - isso parece claro. Já os procedimentos para o "empréstimo" não são claros. Como será o acesso? Poderá ser feito mediante a utilização de dispositivos como o tablet, que será usado no âmbito (físico) da biblioteca? Ou o tablet será emprestado? Ou o leitor inscrito baixará o texto em seu próprio dispositivo por um período de tempo previamente determinado? Restará fazer a escolha possível e que essa seja a melhor para a disseminação de informação. É provável que em poucos anos essas questões possam parecer descabidas. No entanto, no âmbito da cultura jurídica vigente, essas mudanças exigirão novos procedimentos e, talvez, mudanças na legislação.

O terceiro desafio é a organização da nuvem. Na situação atual, cada biblioteca municipal tem a sua própria organização. Parte menor delas, de alguma forma, segue as regras e procedimentos tradicionais da biblioteconomia. A maioria segue critérios próprios e toscos. A biblioteca pública digital terá a sua organização, provavelmente, seguindo padrões internacionais já estabelecidos. Cada leitor, independente de sua localização geográfica, escolaridade ou nível socioeconômico, chegará ao que deseja familiarizando-se com as ferramentas de acesso e busca.

\section{Formas de acesso}

O acesso - eis a grande barreira para a obra digitalizada no Brasil. Os números referentes à porcentagem de brasileiros que têm acesso à Internet são imprecisos. No entanto, pela frequência a lan houses e serviços gratuitos de acesso à Internet, pelo número de assinantes de provedores, pela venda de equipamentos, pelo aumento do volume de compras pela Internet, pode-se avaliar que cerca de $50 \%$ da população, de alguma forma, tem acesso à internet (http://tobeguarany.com/internet_no_brasil.php). É provável que, desse 
número, a maioria seja de crianças e adolescentes, a parte da população que aderiu com mais facilidade e entusiasmo às novas tecnologias de informação.

Para leitura de texto, o dispositivo mais utilizado é o tablet. Ele permite a leitura de livros, revistas e jornais, bem como ouvir música e ver vídeo de forma prática e confortável. Ele aparece em salas de aula, e cada vez mais como substituto de caderno de anotação. Funciona também como biblioteca portátil, uma vez que pode arquivar centenas de livros. $\mathrm{O}$ barateamento progressivo desse equipamento, fator de aumento das vendas, indica que os preços terão baixas mais acentuadas. A Índia produz tablets e vende-os a estudantes pelo preço médio de um livro brasileiro: R\$ 40,00.

Esse quadro sugere que os planos de incremento à leitura e difusão dos livros deverão incluir recursos para dotar as bibliotecas municipais de tablets. Elas, mesmo não dispondo de acervo físico, terão essas portas pelas quais será possível ter acesso a todo o acervo digitalizado e disponível.

\section{Lei de Acesso à Informação}

Uma nova perspectiva para as bibliotecas municipais, entendidas como serviços de informação pública, foi dada pela Lei Federal $\mathrm{n}^{\mathrm{o}}$ 12.527, assinada em 18 de novembro de 2011. O seu artigo $3^{\mathrm{o}}$ deixa claros os objetivos da lei:

"Os procedimentos previstos nesta Lei destinam-se a assegurar o direito fundamental de acesso à informação e devem ser executados em conformidade com os princípios básicos da administração pública e com as seguintes diretrizes: I - observância da publicidade como preceito geral e do sigilo como exceção; II - divulgação de informações de interesse público, independentemente de solicitações; III - utilização de meios de comunicação viabilizados pela tecnologia da informação; IV - fomento ao desenvolvi- mento da cultura de transparência na administração pública; V - desenvolvimento do controle social da administração pública".

E no artigo 9ํำ detalha:

"O acesso a informações públicas será assegurado mediante: I - criação de serviço de informações ao cidadão, nos órgãos e entidades do poder público, em local com condições apropriadas para: a) atender e orientar o público quanto ao acesso a informações; b) informar sobre a tramitação de documentos nas suas respectivas unidades; c) protocolizar documentos e requerimentos de acesso a informações; e II - realização de audiências ou consultas públicas, incentivo à participação popular ou a outras formas de divulgação".

A partir dessas determinações e entendendo as bibliotecas municipais como serviços de informação à coletividade que serve, a lei abre novas perspectivas de sua atuação. Se isso, na atual condição dos acervos públicos, parece inviável, na amplitude que os processos digitais possibilitam, a inclusão dessa ordem de serviço é não só viável, mas necessária. E como a lei "dispõe sobre os procedimentos a serem observados pela União, Estados, Distrito Federal e Municípios", a biblioteca digital pública seria a porta de entrada para o cidadão conhecer o que a lei lhe faculta.

\section{NOVAS PERSPECTIVAS PARA A BIBLIOTECA PÚBLICA}

Para alguns, a biblioteca tradicional nunca vai acabar (como se pensava a respeito do nitrato de prata). Para outros, ela desaparecerá como um órgão que perdeu a função e é eliminado; ou se extingue por atrofia. $\mathrm{Da}$ mesma forma que a fotografia não desapareceu, mas se aperfeiçoou com os recursos digitais, com a biblioteca pública ocorrerá 
o mesmo. A sua função básica - prestar informações necessárias à coletividade - permanece e, com os novos recursos, poderá ser incrementada.

A digitalização do acervo permite a formação e a organização únicas para todos os municípios brasileiros. Mas isso não implica a eliminação das características de cada cidade. Como nas bibliotecas tradicionais dos municípios há um espaço reservado para a inclusão de materiais referentes à cidade, o mesmo deverá ocorrer no plano digital. Assim, cada cidade fará o levantamento dos documentos que lhe são pertinentes: obras sobre o município e suas personalidades, coleções de revistas e jornais antigos, fotos, depoimentos gravados, filmes e outros materiais que formam a sua memória. Esses documentos serão digitalizados e colocados à disposição de estudantes e outros interessados na história da cidade.

Além das informações da memória dos municípios, deverá ser construído o conjunto das informações locais de interesse coletivo. Como os órgãos públicos são regidos pelas mesmas leis e decretos, o que se aplica a um deles será aplicado aos demais com os ajustes necessários. Nesse âmbito, serão incluídas as várias faces da administração, notadamente as que mais se vinculam aos interesses públicos, como o orçamento municipal e sua execução. Da mesma forma, aplica-se ao Legislativo a necessidade de transparência e de acompanhamento de suas atividades.

Em síntese, a biblioteca digital brasileira caracteriza-se como um acervo básico organizado, atualizado permanentemente e oferecido por entidade governamental a todos os municípios brasileiros. No entanto, permanecem os desafios locais de informação que abrangem um vasto arco - do que diz respeito aos direitos básicos do cidadão à ação cultural.

Exemplo disso é a programação cultural que as cidades realizam. Nos municípios maiores, com bibliotecas mais consolidadas como serviço público, elas, normalmente, desenvolvem atividades além do acesso ao acervo, programando palestras, exposições, exibição de filmes, recitais... Essa prática situa-se entre os três verbos que formam a trilogia essencial das bibliotecas públicas: informar, discutir a informação e criar novas informações. Enquanto o primeiro verbo traz as informações demandadas ou propostas, o segundo as discute. Exemplo: exibição de um filme com recursos digitais seguida de debate sobre ele. O terceiro verbo, "criar", é o que dá o sentido maior das atividades de informação e de ação cultural: encontrar respostas, descobrir soluções, enfim, criar novas informações, que envolvam atividades de interesse social direto ou a elaboração de discursos poéticos que se concretizam com a música, textos, sons, corpo e voz. Nesse sentido, as bibliotecas públicas, reunindo e disseminando as informações, criando programas que envolvem a pessoa participativa, estão juntando informação e cultura numa relação dialética, seminal, para produzir, num movimento contínuo, as respostas, sempre provisórias, que a coletividade busca para a superação de seus limites.

Nesse sentido, mesmo com toda tecnologia e virtualidades, as bibliotecas municipais continuarão como espaços físicos e com horários delimitados. Isso ocorrerá porque elas serão os locais das atividades correspondentes aos verbos "discutir" e "criar" - que pedem espaço e tempo -, ao contrário do "informar", que prescinde deles. No entanto, a configuração física da biblioteca tradicional será alterada substancialmente. Nela o espaço destinado ao acervo sempre foi o mais amplo, quando não, praticamente, o único. Como não há previsão de armazenamento físico de acervo, novos espaços deverão ser propostos.

Há, ainda, uma possibilidade de ação que só as novas tecnologias permitem: a expansão de terminais para outros ambientes da cidade. Por meio de painéis interativos poderão ser levadas informações de interesse público a quaisquer cidadãos em qualquer lugar. Da mesma forma, os serviços da biblioteca poderão ser oferecidos remotamen- 
te a quaisquer instituições, notadamente as de ensino. Durante uma aula, o acervo da biblioteca digital, principalmente de vídeos, poderá ser acessado.

Novos estudos deverão ser desenvolvidos, mas, com a disponibilidade da tecnologia já existente, os benefícios tornarão a relação custo/benefício plenamente favorável às novas possibilidades. Assim, o jovem da cena inicial da biblioteca poderá frequentá-la para usufruir de suas atividades, e a biblioteca, aparentemente sem função, terá caminhos de expansão, saindo de suas quatro paredes e se expandindo para toda a cidade. 